\title{
Transtorno e déficit de atenção e hiperatividade: integrando terapia complementar ao cuidado da criança/adolescente
}

\section{Attention deficit hyperactivity disorder: integrating complementary therapy to care of children/adolescents}

\author{
Juliane Pagliari Araujo'; Luciana Cláudia Rizzo Lima²; Juliana Gomes Fernandes; \\ Simone Roecker ${ }^{4}$; Jackeline Tiemy Guinoza Siraichi ${ }^{5}$
}

\begin{abstract}
Resumo
O estudo objetivou identificar o conhecimento de cuidadoras de crianças e adolescentes sobre o Transtorno e Déficit de Atenção e Hiperatividade (TDAH) e suas percepções quanto às mudanças no cotidiano e no convívio familiar após a participação em sessões de massagem Tui Na. Foram realizadas entrevistas semiestruturadas gravadas nos meses de setembro a novembro de 2013, com nove cuidadoras das crianças e adolescentes com diagnóstico de TDAH que participaram das sessões de massagens. Os dados foram submetidos à análise de conteúdo, com uma abordagem qualitativa. Identificou-se que algumas mães possuem pouco conhecimento sobre o transtorno dos filhos. Com relação à participação das crianças e adolescentes, foi relatado melhora na comunicação com a família, mais tranquilidade logo após a massagem, sono sereno, melhora do humor e rendimento escolar. As cuidadoras relataram que a participação das crianças e adolescentes nas sessões de massagem Tui $\mathrm{Na}$ foi produtiva, com aceitação por parte das crianças e adolescentes e com mudanças positivas no cotidiano e no convívio familiar. As participantes do estudo apontaram que enfrentar as dificuldades do TDAH no dia a dia faz com que ocorra a aproximação com seu filho, diminuindo a ansiedade e melhorando a qualidade de vida de toda a família. $\mathrm{O}$ compartilhamento de informações entre os profissionais de saúde e a família das crianças e adolescentes sobre o TDAH faz-se importante para a compreensão das mães sobre a patologia, bem como, para o acompanhamento e prosseguimento do tratamento.
\end{abstract}

Palavras-chave: Transtorno do déficit de atenção com hiperatividade. Massagem. Família. Criança. Adolescente.

\begin{abstract}
The study aimed to identify the knowledge of caregivers of children and adolescents about the Attention Deficit Hyperactivity Disorder (ADHD) and their perceptions regarding changes in daily and family life, after participating in sessions of Tui Na massage. Semistructured interviews in the months from September to November 2013 were held, with nine caregivers of children and adolescents diagnosed with ADHD who participated in massage sessions. The data were subjected to content analysis with a qualitative approach. It was identified that some mothers have little knowledge about the disorder of their children. Regarding the participation of children and adolescents, it was related a positive response, an immediate valuable result, with improved communication with family, more tranquility after the massage, restful sleep, improved mood and better performance school. The caregivers of children and adolescents related that their participation in the Tui Na massage sessions was productive, with acceptance by them with positive changes in daily and family life.
\end{abstract}

\footnotetext{
${ }^{1}$ Enfermeira. Mestre em Biociências e Saúde. Docente do Colegiado de Enfermagem do Instituto Federal do Paraná - Campus Londrina, Paraná, Brasil. E-mail julianegio@hotmail.com

${ }^{2}$ Técnica em enfermagem. Especialista pós-técnico em saúde do trabalhador. Hospital Evangélico de Londrina, Paraná, Brasil. E-mail: lucianaclaudiar@hotmail.com Fisioterapeuta.

${ }^{3}$ Especialista em Dermato Funcional. Docente do Colegiado de Massoterapia do Instituto Federal do Paraná - Campus Londrina, Paraná, Brasil. E-mail: juliana.fernandes@ifpr.edu.br Enfermeira.

${ }^{4}$ Mestre em Enfermagem. Docente do Colegiado de Enfermagem do Instituto Federal do Paraná - Campus Londrina, Paraná, Brasil. E-mail: simone.roecker@ifpr.edu.br Fisioterapeuta.

${ }^{5}$ Doutora em Ciências Farmacêuticas. Docente do Colegiado de Massoterapia do Instituto Federal do Paraná - Campus Londrina, Paraná, Brasil. E-mail: jackeline.guinoza@ifpr.edu.br
} 
The study participants pointed that daily difficulties of ADHD approach them to their son, decreasing anxiety and improving the quality life for the whole family. Sharing information between health professionals and family of children and adolescents about ADHD is important to understand the pathology, as well as for monitoring and further treatment.Palavras-chave: Transtorno do déficit de atenção com hiperatividade. Massagem. Família. Criança. Adolescente.

Keywods: Waste products. Environmental education. Food handling.

\section{Introdução}

O Transtorno e Déficit de Atenção e Hiperatividade (TDAH) é caracterizado por desatenção, hiperatividade e impulsividade, com maior prevalência na infância (PAIANO et al., 2007; ROHDE et al., 2000). Em 2004, nos Estados Unidos da América (EUA), o TDAH foi oficialmente considerado "um dos problemas mais graves e importantes da saúde pública americana." (CALIMAN, 2008, p. 560). Em estudo de metaanálise, relatam que $5,29 \%$ da população mundial apresentam TDAH (POLANCZYK et al., 2012).

As manifestações clínicas do TDAH normalmente ocorrem antes dos sete anos de idade e podem persistir até a vida adulta (DESIDÉRIO; MIYAZAKI, 2007). Esse transtorno envolve inúmeras dúvidas em relação ao tratamento, seja dos pais, professores e todos os envolvidos na vida da criança e do adolescente que apresenta essa patologia. Além dessas dúvidas, a falta de conhecimento e apoio especializado contribui para que esta criança/adolescente seja definida como má educada, indisciplinada e em alguns casos pouco inteligente (SILVA, 2003).

No convívio familiar, é esperada a participação dos pais no cuidado e na educação, e que estes contribuam para o sucesso e desenvolvimento saudável de seus filhos, exercendo uma gama de habilidades que reflitam no cotidiano da criança e da família (SENA; SOUZA, 2013). Desta maneira, o estresse cotidiano em que os pais vivem pode influenciar a sua maneira de agir no ambiente familiar, educacional e social do seu filho(a), trazendo prejuízos à sua saúde (APA, 2000).
Famílias com crianças portadoras de TDAH experimentam rotinas diferentes em relação com outras famílias que não enfrentam o mesmo tipo de problema. Nesse sentido, quem muito sofre com as consequências do TDAH são as mães, por ver seu filho sendo estigmatizado. Ela, em muitos casos, se considera a maior responsável pela educação e inserção de seu filho na sociedade (PHELAN, 2005, BRZOZOWSKI; CAPONI, 2009).

Visando a inserção da criança no contexto social, os pais tem procurado alternativas para o tratamento da sintomatologia dos seus filhos(as). Estudo aponta a importância da abordagem global e interdisciplinar, o que inclui as intervenções farmacológicas e psicossociais (DESIDÉRIO; MIYAZAKI, 2007).

Salienta-se ainda a importância da intervenção complementar realizada por meio da massagem Tui $\mathrm{Na}$, como um tratamento alternativo importante para a promoção do relaxamento e controle da agitação (ROSSI, 2010).

A técnica de massagem tem como objetivo proporcionar confiança, melhorar a circulação, desenvolver a percepção corporal, e também a permissão para ser tocado, desacelerar o corpo e a mente da criança, proporcionar tranquilidade e desenvolver a autoestima, melhorar o relacionamento e a comunicação com os que participam do seu ciclo de relacionamento, como pais e amigos (COSTA et al., 2010), além de ir ao encontro com as expectativas das mães em ter algo que auxilie seus filhos a superar as dificuldades vividas no cotidiano (ROSSI, 2010).

A massagem Tui $\mathrm{Na}$ é uma técnica de origem Chinesa que enfatiza a relação integral do corpo 
humano com a natureza, atuando no fluxo de energia vital do corpo, proporciona efeitos benéficos que se traduzem em saúde e bem estar emocional, intelectual, espiritual e físico (LOPES, 2010). Além de favorecer a saúde e bem-estar, proporcionando efeitos positivos na impulsividade, agitação, falta de concentração, fragilidades emocionais e distúrbios do sono, além de atuar no desenvolvimento musculoesquelético e na coordenação motora (MERCATI, 2000).

Face ao exposto, o objetivo desse trabalho foi identificar o conhecimento de cuidadoras sobre TDAH e suas percepções quanto às mudanças no cotidiano e no convívio familiar das crianças e adolescentes portadores de TDAH, após a participação em sessões de massagem Tui Na.

\section{Método}

Trata-se de um estudo descritivo-exploratório com abordagem qualitativa.

As participantes da pesquisa foram nove cuidadores de crianças/adolescentes, das quais, oito eram mães e uma era avó da criança, sendo incluída por caracterizar-se como principal cuidador. As crianças que participaram de 12 sessões de massagem Tui $\mathrm{Na}$ estavam matriculadas entre o quinto e o oitavo ano de uma escola estadual no município de Londrina - PR, com idade entre 10 e 14 anos.

Onze crianças e adolescentes participaram do projeto, no entanto, nove entrevistas foram realizadas, sendo que duas mães tinham mais que um filho inscrito no projeto. Foram incluídas no projeto as crianças/adolescentes que possuíam laudo médico com o diagnóstico de TDAH e que os pais autorizassem a participação. A seleção das crianças e adolescentes foi realizada pela própria escola. Foram conduzidas reuniões com os pais e com as crianças/adolescentes orientando-os sobre a metodologia do trabalho, bem como, demonstrado como seria realizada a massagem Tui Na. Todas as etapas do projeto, referente às intervenções da massagem Tui Na nas crianças/adolescentes, foram realizadas na escola onde as crianças/adolescentes estudavam, por ser um ambiente de confiança e com o objetivo de diminuir medo e ansiedade pelo desconhecido.

As sessões de massagem Tui $\mathrm{Na}$ foram realizadas nos meses de junho a agosto de 2013 por estudantes do curso técnico em Massoterapia, acompanhadas por estudante do curso técnico em Enfermagem, ambos do último ano do curso, e ocorreram em uma sala de aula, sem controle de ruídos externos e temperatura. Todo estímulo visual como painéis para leitura foram retirados. A sequência da massagem Tui Na foi padronizada e realizada sobre a maca, com a criança vestindo roupas confortáveis (uniforme escolar: calça e camiseta) e sem lhe causar qualquer espécie de constrangimento. Cada sessão teve a duração de 40 minutos, três vezes na semana, totalizando 12 sessões.

A sequência da massagem Tui Na contemplou seis repetições dos movimentos Tui $\mathrm{Fa}, \mathrm{Na} \mathrm{Fa}$, Mou $\mathrm{Fa}$, Zhen $\mathrm{Fa}$, Ban $\mathrm{Fa}$, Yao Fa, Nien $\mathrm{Fa}$ realizados em todo o corpo iniciando na posição decúbito ventral seguido de dorsal, além de An Fa harmonizando os pontos VG20, R1, VC6, VC8 VC12, VC17, VC22, C3, ID3, IG4, Ext3, ID19, E2, IG20, VG26. A quantidade e a duração das sessões foram determinadas a partir do relato de estudo apresentado por este grupo, no qual os resultados alcançados indicaram melhora no comportamento da criança com TDAH (SIRAICHI et al., 2013).

A coleta de dados foi realizada pela estudante do curso técnico em Enfermagem, orientada por docentes de ambos os cursos, entre os meses de setembro a novembro de 2013, após o término das doze sessões de massagens, sendo conduzida por meio de entrevista semiestruturada, as quais foram agendadas pelos pesquisadores, previamente via telefone. As entrevistadas indicaram o local (domicílio) e horário, conforme a sua disponibilidade. 
As participantes foram orientadas a respeito da entrevista semiestruturada, e após o esclarecimento das dúvidas, assinaram o Termo de Consentimento Livre e Esclarecido. Os dados foram gravados em gravador digital, transcritos e as gravações foram apagadas posteriormente. Foi utilizado um roteiro de entrevista, constituído de duas partes: a primeira, com questões objetivas referentes ao perfil sociodemográfico e a segunda, com questões abertas relacionadas ao conhecimento das mães sobre o TDAH e suas percepções sobre os efeitos da massagem Tui Na no cotidiano e no convívio familiar da criança/adolescente.

Após transcrição na íntegra e sem interpretações dos relatos, foram realizadas leituras, seguida da análise de conteúdo. Dentre as diferentes técnicas de análise de conteúdo, optou-se pela análise categorial, que ocorre por meio de atividades de desmembramento do texto em categorias segundo agrupamentos analógicos (BARDIN, 2011). Após a categorização das falas, procedeu-se, então, à inferência por meio dos dados obtidos e utilizando como base teórica o material disponível em publicações científicas acerca da temática em estudo. A partir dessa análise, emergiram duas categorias: "O que é esse "tal" de TDAH?" e "Será que essa massagem funciona?" Para diferenciar e preservar a identidade das mães utilizou-se como código a letra ' $\mathrm{M}$ ' seguida de numeral arábico, de acordo com a ordem de realização das entrevistas (M01 a M09).

Esse trabalho faz parte de um projeto intitulado "Intervenção da massagem Tui $\mathrm{Na}$ na criança/ adolescente com Transtorno e Déficit de Atenção e Hiperatividade" desenvolvido em parceria entre os cursos técnico em Massoterapia e Enfermagem do Instituto Federal do Paraná - Campus Londrina. A pesquisa seguiu a Resolução vigente do Conselho Nacional de Saúde (BRASIL, 2012) e foi aprovada pelo Comitê de Ética em Pesquisa Envolvendo Seres Humanos da Universidade Federal do Paraná (CAAE: 13924113.7.0000.0102, Parecer 391.470/2013).

\section{Resultados e Discussão}

\section{Perfil das cuidadoras de crianças e adolescentes portadores de TDAH}

Das participantes dessa pesquisa, oito eram mães e apenas uma era avó da criança. A idade das mães variou entre 33 e 48 anos, e a avó tinha 67 anos. Das nove entrevistadas, seis eram casadas, duas solteiras e uma viúva.

A variação é de dois a três filhos por família, sendo que, duas famílias possuíam dois filhos com diagnóstico de TDAH.

No que tange à escolaridade, quatro mães completaram o ensino médio, quatro possuíam somente o ensino fundamental, e a avó era alfabetizada. Verificou-se que a renda familiar variou entre dois a cinco salários mínimos, e em todas os casos as mães contribuíam para o sustento da família, trabalhando com registro em carteira, ou com renda informal. Quanto à religião, cinco mães declaram-se católicas e quatro evangélicas.

Como as entrevistas foram realizadas no domicílio, percebeu-se que todas as casas eram cuidadas, limpas, bem divididas e espaçosas, com pelo menos um quarto exclusivo para as crianças/ adolescentes. As famílias cujos filhos eram um casal, ou mais, esses dormem cada um em seu quarto, separando as meninas dos meninos. Verificou-se ainda, que, todas moravam em casas de alvenaria, com energia elétrica e água encanada, apenas uma entrevistada relatou que na sua casa o sistema de despejo dos dejetos era por meio de fossa.

O estudo buscou desvelar o conhecimento que as cuidadoras de crianças e adolescentes possuíam sobre o TDAH e a sua estreita relação com as mudanças no cotidiano e convívio familiar. Pois, acredita-se que, para estarem preparadas a perceber as mudanças e desenvolver o cuidado aos portadores de TDAH elas precisam, primeiramente, ter conhecimento do universo que tange essa patologia, para então serem capazes de expressar as 
suas percepções sobre as mudanças evidenciadas em seus filhos após as sessões de massagem Tui $\mathrm{Na}$.

Ante o exposto, apresentam-se as categorias elucidadas a partir dos depoimentos das cuidadoras participantes desse estudo:

\section{O que é esse "tal" de TDAH?}

Embora uma mãe tenha apresentado uma definição do TDAH que se aproxima daquela da literatura dizendo "É dificuldade de aprendizagem né, de se concentrar [...]" (M04), as demais participantes não pareceram ter conhecimento sobre o que é o transtorno. Durante as entrevistas isso foi evidenciado como neste relato: "Bom, não sei te falar, acho que ele ficou assim por algum problema sabe [...]" (M08).

Em uma entrevista a mãe associou o TDAH com problemas relacionados às dificuldades enfrentadas com sua situação conjugal.

Foi muito difícil para ele quando me separei, ele enfrenta isso assim, é o jeitinho dele enfrentar isso (M08).

Duas mães fazem associação do TDAH com problemas relacionados ao parto ou nascimento de outro filho.

O problema dele é sério porque é uma sequela que deixou ele assim. Porque faltou oxigênio no cérebro dele, então ele usou Gardenal ${ }^{\circledR}$ e a sequela que ficou foi da hiperatividade (M01).

A partir de uns cinco anos de idade, mais ou menos, ele era muito calmo, muito tranquilo, era um bebê que não vinha nem no colo, era um bebê que onde você largasse ele ficava, só que quando nasceu o segundo, foi onde a gente sentiu essa transformação, o terceiro, quero dizer, o terceiro, ele estava com cinco anos, a gente achou que essa transformação veio depois disso, ciúme mesmo, ele demonstrava, ele tentava ir no berço e fazer alguma coisa com o outro, ele dava um jeitinho, se outro estava sentadinho no chão ele dava um jeito de passar e pisar na mão, pisar na perna, e tinha que estar sempre atento, tem que estar sempre atento (M09).
$\mathrm{Na}$ maioria dos casos é difícil para a família entender o comportamento de seus filhos e aceitar o diagnóstico, devido, principalmente, à falta de informação sobre o TDAH (BRZOZOWSKI, CAPONI, 2009). No presente estudo, muitas cuidadoras relacionaram o problema dos filhos a algum acontecimento, trauma, ou qualquer ocorrência dentro da própria família como fator gerador desse problema em seus filhos.

Culturalmente, as mães são mais responsabilizadas pelos cuidados e educação dos filhos, são elas que também, na maioria das vezes, recebem as queixas e dificuldades apresentadas pelas crianças em diferentes situações. Nesse sentido, e considerandose que se vive em uma sociedade que culpa os pais por tudo o que os filhos fazem, eles, e em especial a mãe, estarão constantemente tentando descobrir o que deu errado com a criança, o que elas fizeram de errado, demostrando assim o sentimento de incompetência no cuidado ao filho (PHELAN, 2005).

Estudos de avaliação sobre TDAH identificaram como causa, uma taxa de hereditabilidade de $76 \%$ relacionadas a famílias, crianças adotadas e gemelares, afirmando a contribuição genética como uma forte influência para a patologia (BIEDERMAN, 2005; POLANCZYK et al., 2012). Outro estudo considera que mesmo considerando o TDAH como um transtorno multifatorial de base neurobiológica, ainda, o diagnóstico é realizado basicamente por meio de avaliação de elementos comportamentais, o que pode gerar um julgamento subjetivo, pois é utilizado como base o roteiro do Manual Diagnóstico e Estatístico de Doenças Mentais (DSM-IV) (LARROCA; DOMINGOS, 2012). Este tipo de julgamento pode ser evidenciado no relato de duas mães que dizem que o TDAH tem como características a criança "sem limites", que "não para".

\footnotetext{
Uma criança que não para quieta, fala muito, ela não tem assim, limite, é uma criança que tem dificuldade em aprendizagem porque não para [...] (M03).

É uma criança que não tem parada, não fica quieta [...] (M02).
} 
Estudo apontou que crianças que foram diagnosticadas com TDAH não apresentavam sinais que definissem tal transtorno, pois não satisfaziam os critérios do DSM-IV (LARROCA; DOMINGOS, 2012).

A indústria farmacêutica e centros de pesquisa e saúde propagam o discurso da patologização, de classificar o indivíduo com mau comportamento, falta de atenção e agitado em função de um diagnóstico e sua direta associação ao medicamento. Verdade construída pelo mercado que tem contribuído com potencial aumento de portadores de TDAH na população (ORTEGA et al., 2010; REIS; SANTANA, 2010).

Nesse transtorno é comum alguns membros da família serem extremamente rigorosos em alguns casos, e complacentes em outros. E não conseguem compreender como, a mesma criança que não consegue se concentrar nos deveres escolares, por exemplo, passa horas jogando vídeo game. Isso também foi evidenciado nesse estudo, fomentando discussão sobre a falta de informações das mães (SILVA, 2003).

Uma coisa que a gente acha engraçado, ele tem essa deficiência de atenção, mais no computador ele fica horas e horas, no vídeo game, ele fica horas e horas, o negócio dele é jogar, ele é fanático por jogo, então ele fica horas e horas ali no computador jogando, no vídeo game jogando e ele fica horas e horas com o celular no ouvido, só ouvindo música [...] (M09).

É bem provável que a maior dificuldade em relação ao TDAH está no fato de que ainda existe pouco conhecimento sobre este assunto tanto no ambiente escolar, como entre os pais e demais familiares. Muitos indivíduos que são acometidos por essa patologia podem passar a vida toda sendo vistos como maleducados, preguiçosos, desastrados, desequilibrados, justamente porque não foi diagnosticado e tratado corretamente (SAMPAIO, 2004). E, pela falta de informações e pelas rotulações, os pais de crianças com TDAH têm experimentado desafios no cuidado e educação de seus filhos (SENA; SOUZA, 2013).
Tanto do G., quando do W., no colégio foi difícil. $\mathrm{O}$ G. principalmente, todo o tempo, eu tive que até assistir aula, vários dias, e o comportamento que eles me passaram é que o G. estava tendo um comportamento agressivo, desrespeitou a professora, não acata a ordem. É o professor falar para fazer, ele fala assim: eu não vou fazer, e ponto final, não fazia, sabe, teve até alguns momentos que teve que colocar para fora da sala de aula, estressou bastante [...] (M03).

Durante as entrevistas, identificou-se que o conhecimento dos pais sobre TDAH é ainda restrito, sendo que a fala é direcionada para a escola, para o comportamento no ambiente escolar e para o processo de aprendizagem, deixando de ver a criança como um todo em todos os ambientes que ela convive. Salienta-se que cabe aos profissionais de saúde, orientar os pais sobre a patologia, bem como, a maneira de como agir com a criança, a fim de integrar a família.

\begin{abstract}
Nem tudo que a gente fala eles tomam conhecimento, você pode falar, falar, falar, que é difícil cair a ficha, para aprender então, só Deus. Nossa é difícil, e na escola também o professor reclama bastante, porque não para sentado, conversa demais, não presta atenção na aula, está voado, então a gente vê mais a dificuldade na escola [...] (M07).
\end{abstract}

Apesar da falta de informações e conhecimento dessa patologia pelas mães e pelas dificuldades enfrentadas no seu cotidiano, as mesmas buscam auxílio, ajuda e informação conforme possibilidades.

Dessa forma, as mães, por conviver com os comportamentos do TDAH, e conhecer o sofrimento do filho e seu também, buscam alternativas para ajudar o filho. Outras atividades, como prática de esportes são inseridas na rotina da criança com o intuito de melhorar seu quadro, com a intenção talvez de ocupar a cabeça dessa criança, ou na tentativa de dominar um comportamento descontrolado (BALBI et al., 2008).

Entende-se que para as famílias é difícil acreditar que seu filho sofre deste transtorno, mas 
cabem a elas tomar as devidas providências para compreender e ajudar seus filhos, para que estes convivam em harmonia e tranquilidade na escola, no lar e em sociedade (FIGUEIRA; SILVA, 2010).

Diante do exposto, torna-se mais difícil o tratamento e acompanhamento da criança e alguns pais, no início, por desespero, mantém a teoria de que nada está errado, e pode ser corrigido por meio de conselhos, orientações ou estratégias mais simples para controlar o comportamento de seus filhos (SCHILK, 2007).

[...] muitas vezes só conversando com ela, às vezes é um problema que a criança tem lá dentro dela, é uma coisa que está lá, guardadinho, e no conversar, aquilo é colocado, não precisa tomar o remédio, tudo se ajeita, muitas vezes é uma coisinha insignificante, que pode ser resolvido sem medicamento, então o que a gente ia tentar agora é isso, seria fazer essa sessão com a psicóloga pra ver se vai ter uma mudança (M09).

Para a melhor compreensão dos pais em relação ao TDAH, é necessário ampliar e difundir informações corretas sobre o diagnóstico, as causas, as manifestações no cotidiano familiar e escolar, as formas de tratamento. Essas ações por profissionais de saúde tendem a facilitar a convivência familiar e escolar, visto que é uma criança que necessita de uma atenção especial.

Diante dos depoimentos apresentados é possível afirmar que as mães possuem limitações quanto ao conhecimento sobre o TDAH. Nesse contexto se faz necessário aceitar o TDAH como um problema real e procurar saber como agir com seu filho, pois os pais devem ajudar as crianças a compreenderem suas dificuldades, uma vez que elas próprias não têm um entendimento sobre a sua patologia (TEIXEIRA, 2013).

\section{Será que essa Massagem Funciona?}

As mães das crianças que participaram das sessões de massagem Tui Na apontaram satisfação com os resultados positivos.
Foi ótima, retorno muito positivo [...] com a massagem ele ficou mais tranquilo. Então, a gente está vendo melhoras nele constante, ele está bem mais calmo, com a massagem ele chegava aqui (em casa) bem mais calmo, a gente viu, retorno muito positivo (M01).

Eu achei uma maravilha, na realidade nunca imaginei que uma escola pública pudesse ter um projeto como esse, na realidade eu acompanhava ele durante a massagem [...], e é ótimo sem dúvida nenhuma [...] (M06).

Eu fiquei contente, gostei, eu sabia que ele ia melhorar, porque quando a pessoa participa de alguma coisa que é para ajudar, acaba melhorando [...] (M05).

A partir dos depoimentos desse estudo, salientase que projetos e terapias direcionadas às crianças com transtorno podem auxiliar na melhora contínua dos sintomas característicos do TDAH, visto que aceitação de pais e crianças/adolescentes foi satisfatória.

Este resultado corrobora com pesquisa realizada nos EUA que apontou o efeito da terapia de massagem em vinte e oito adolescentes com TDAH, e foi registrado que ficaram mais alegres e menos inquietos após as sessões, e após duas semanas estavam permanecendo mais tempo em sala de aula e menos hiperativos do que anteriormente (ARAUJO; SILVA, 2003).

Assim, considera-se que a massagem pode ser uma alternativa eficiente para crianças com TDAH, um auxílio importante para o tratamento da hiperatividade, junto ao tratamento medicamentoso, trazendo maior resultado em médio prazo.

\footnotetext{
Foi assim boa, foi tranquila [...] ele gostou, ajudou bastante, ele ficou bem mais tranquilo, e isso, não ficou mais tão agitado do jeito que ele ficava. Mudou bastante, ajudou muito [...] (M02).

A gente está vendo melhoras nele constante, [...] ele mesmo foi gostando, ele já vinha até dormindo no carro, colocava a musiquinha mais calma na hora que eu pegava ele, então a gente viu retorno muito positivo (M01).
}

As mães perceberam uma resposta positiva nos seus filhos em relação à participação deles, alguns 
com reações diferentes inicialmente, por ser algo novo.

Ele teve uma resistenciazinha depois que ele começou [...] o importante é ele está gostando, mesmo que ele não tenha aquele resultado de imediato que a gente está esperando, mas ele está gostando daquilo e para mim é bem importante (M04).

É compreensível que as mães esperem um resultado imediato na terapia, visto que sempre estão à procura de algo que lhes deem uma resposta mais efetiva no tratamento.

Ele estava levando mais a sério, chega em casa animado, nos dias de massoterapia, fica lá numa boa, não reclama, deu uma aliviada, só o fato dele ter interesse na massoterapia, já é um passo, já é alguma coisa, e fazer uma coisa que ele está gostando, e levando adiante $[\ldots]$ (M07).

Houve diferentes percepções das mães em relação à participação dos filhos, enquanto uns relataram mais agitação do filho no início do tratamento, outras já expressam que logo no início perceberam mudança de humor, como: calma, ânimo e mais comunicativo.

Foi muito boa [...] nas duas primeiras semanas que ele começou a fazer, eu percebi que ele ficou mais agitado [...] depois que ele foi voltando ao normal, mais calmo, mais tranquilo, mais foi muito bom (M06).

Foi legal, ele ficava animado, ele dizia pra mim: 'mãe, amanhã tem massagem viu, vou chega mais tarde', ele não conversava antes, ele começou a se comunica mais, ele gostava muito, foi muito bom mesmo (M08).

A importância de ver seu filho inserido em uma atividade que lhe causa satisfação, entusiasmo, contentamento também pôde ser percebida, essas mães veem seu filho respondendo bem a uma terapia que tem enfoque na sua patologia.

Ele aceitou, aceitou muito bem, até quando ele chegava e falava: ah vó gostei! (M05).
Foi possível perceber que existe uma satisfação em ver, pelo relato dos filhos, ao retornar da massagem, um resultado positivo na terapia, vendo seus filhos respondendo bem a um tratamento prazeroso e relaxante.

As mães e avó identificaram um resultado imediato em relação ao relaxamento, visto que a massagem Tui $\mathrm{Na}$ causou uma desaceleração do movimento corporal causada pelo toque e pelo ambiente tranquilo e relaxante.

Na realidade ele, tinha dia que ele dormia mesmo na hora da massagem, ele gostava muito da massagem $[\ldots](\mathrm{C} 6)$.

As mães expressaram à interação da família após as massagens, visto que há uma maior comunicação da criança com a família, e expressando em casa o que aprendeu durante as sessões de massagem.

Esse tipo de terapia proporciona um complemento de outras abordagens terapêuticas, mas o sucesso de qualquer tratamento se deve também à participação dos pais, assim como ser integrado em todos os ambientes em que esta criança convive. É importante a participação dos pais, visto que o lar deve ser um complemento do ambiente proposto nas terapias, devendo ser o mesmo tranquilo, com rotinas estabelecidas, os pais devem evitar a superexcitação e o cansaço excessivo da criança, tendo importante participação no sucesso de todo tratamento proposto à criança com TDAH (ARAUJO; SILVA, 2003).

$\mathrm{O}$ pai às vezes estava meio irritado, e eles iam imitar a massagem que foi feita, então isso é bacana, a gente viu o retorno que estava tendo porque eles estavam assimilando mesmo o que era para ser feito, o trabalho realmente [...] Então eles faziam, batia a mãozinha sabe, assoprava, então foi muito bacana (M01).

Ele queria fazer massoterapia em mim, ele me colocava na cama, esticava minha perna, ia lá em cima e voltava, falando igual à mulher que faz a massoterapia nele, o jeitinho que ela falava com ele, ele falava comigo: vamos virar! Você gostou? Está bom? Eu não aguentava, acabava rindo dele. Ele disse que teve dia que ele cochilou (M07). 
Essa interação familiar mostra-se importante fator de percepção do resultado obtido durante as massagens, visto que uma criança que muitas vezes é censurada por atitude impulsiva e inconstante, nesse momento está sendo aprovada nas suas atitudes, mostrando assim que a experiência foi proveitosa.

As famílias com uma ou mais crianças com TDAH experimentam diferenças fundamentais em sua vida cotidiana, com as quais outras famílias não têm de lidar. O transtorno altera drasticamente a vida dessas famílias, já que há mais tensão e mais discussão (PHELAN, 2005).

Os pais de crianças com TDAH também sofrem grande nível de estresse, pelo fato de estarem anos correndo atrás de uma criança hiperativa, de escutar reclamações de todos os lados, como vizinhos, família, escola e amigos sobre o comportamento do seu filho, mesmo os pais mais habilidosos em cuidar de seus filhos podem mostrar-se cansados diante das constantes exigências de uma criança com TDAH, portanto a terapia Tui $\mathrm{Na}$ vai ao encontro à expectativa dos pais em encontrar algo que dê satisfação ao filho e ainda tem como resultado uma resposta positiva em relação ao transtorno (SINCLAIR, 2008).

Dessa forma, quanto mais integrados estiverem os pais, tanto no sentido emocional, quanto no comportamental, melhor estará o filho. Isso não quer dizer que os pais causem o transtorno, mas, se os pais forem suficientemente racionais, competentes e inteligentes, o filho estará melhor (KUNRATH; WAGNER, 2009).

As alterações no convívio familiar foram descritas em todas as entrevistas, existindo uma concordância em relação à melhora do humor, bem como da comunicação da criança.

Foi muito bom, ele não era de conversa, ele não se comunicava, ele começou a se comunica mais, agora não para de fala, se expressa melhor, conta as coisas, muito legal a evolução dele [...]. Mas a comunicação foi o que melhorou mais (M08).
Eu acho que ele melhorou, ele não é mais aquele M. de antes, ele está conseguindo se manter mais tranquilo, mais assim, mesmo ele não perde a hiperatividade, ele melhorou um pouco sim, ele não está assim, igual ele era antes, não está tão agressivo, ele era muito agressivo, ele esta mais tranquilo (M09).

Desta forma podemos inferir que o resultado obtido em curto prazo foi positivo para as famílias que têm uma ou mais crianças com diagnóstico de TDAH, visto que todas tiveram um relato positivo sobre a melhora do convívio familiar dessas crianças, como já mencionado anteriormente. Sendo que no final das entrevistas, as mães relataram a vontade de que continuasse o projeto proposto, pois acreditavam no seu resultado.

\begin{abstract}
Ah, eu só tenho a agradecer o projeto. Eu acho que se vocês tiverem a oportunidade, eu sei que é difícil porque é pouco, mas se vocês puderam aumentar, é bom. Porque para meu filho, que é um caso mais delicado, foi excelente e se fosse utilizado já no início do ano, eu acredito que... sabe? Eu fiquei muito feliz, fiquei muito satisfeita mesmo, muito realizada, o carinho das meninas, muito carinhosas, muito atenciosas, amorosas, eles pegaram um afeto muito grande. Então assim, foi demais, eu só tenho a parabenizar, porque foi um retorno muito positivo (M01).
\end{abstract}

Eu gostaria que continuasse, pois foi muito bom, e as crianças precisam de alguém que ajude (M08).

Esse contato com mães de crianças com TDAH fez-nos conhecer suas dificuldades, suas lutas diárias para dar uma vida digna aos seus filhos, no que se refere à educação, vida familiar e social, e tantos outros aspectos que envolvem a vida dessas crianças e seu sucesso no futuro.

\section{Considerações Finais}

O estudo permitiu identificar que as mães, em sua maioria, possuem conhecimento restrito em relação ao transtorno que os filhos sofrem. Nessa perspectiva, o compartilhamento de informações 
entre os profissionais de saúde e a família das crianças/ adolescentes sobre o TDAH faz-se importante para a compreensão das mães sobre a patologia, bem como, para o acompanhamento e prosseguimento do tratamento. $\mathrm{O}$ entendimento das mães sobre como enfrentar as dificuldades do TDAH no dia a dia faz com que ocorra a aproximação com seu filho, diminuindo a ansiedade e melhorando a qualidade de vida de toda a família.

Com relação à participação das crianças e adolescentes nas sessões de massagem Tui Na, percebeu-se uma resposta positiva, tendo um resultado imediato valioso, com melhora na comunicação com a família, mais tranquilidade logo após a massagem, sono tranquilo, melhora do humor e melhor rendimento escolar. Porém, seria importante fazer reavaliações posteriores para avaliar se os efeitos da terapia da massagem conseguem ser mantidos a longo prazo, bem como, avaliar a percepção do pedagogo e professores que acompanham estas crianças/ adolescentes para verificar se a melhora do convívio familiar teria influência sobre o desempenho escolar das mesmas.

A participação das crianças/adolescentes nas sessões de massagem Tui $\mathrm{Na}$ foi produtiva, com aceitação por parte das crianças e adolescentes e com mudanças positivas logo no início da terapia. Contudo, destaca-se que o tratamento do TDAH envolve uma abordagem múltipla, englobando intervenções psicossociais, educacionais e psicofarmacológicas. A partir dessa compreensão, identifica-se a necessidade de espaços de apoio para as crianças e seus pais, potencializando os recursos existentes dentro dessas famílias, para que todos possam melhor lidar com as dificuldades desse transtorno. Dentre esses espaços sugere-se a psicoterapia para as crianças e os pais, intervenção medicamentosa, as intervenções complementares, como a massagem Tui $\mathrm{Na}$, bem como orientação por profissionais de saúde às escolas, aos professores e aos familiares.

Recomenda-se a continuação de estudos em relação a essa questão, assim como analisar novas situações e, ainda, propor a elaboração de estratégias integradas entre as áreas de saúde e educação, que se construam de formas cada vez mais eficazes no auxílio da tarefa de educar os filhos, aqui, em especial, os portadores de TDAH.

\section{Referências}

APA - AMERICAN PSYCHIATRIC ASSOCIATION. Diagnostic and statistical manual of mental disorders. 5. ed. Washington, 2000 .

ARAUJO, M.; SILVA, S. A. S. Comportamentos indicativos do transtorno de déficit de atenção e hiperatividade em crianças: alerta para pais e professores. Revista Digital, Buenos Aires, Ano 9, n. 62, 2003. Disponível em: <http:// www.efdeportes.com/efd62/atencao.htm/> Acesso em: 10 mar. 2013

BALBI, C.; RIBEIRO, C. A.; BORBA, R. I. H.; OHARA, C. V. S.; PINTO, J. P. Compreendendo a vivência de ser mãe de uma criança com transtorno de déficit de atenção e hiperatividade. Revista da Sociedade Brasileira de Enfermeiros Pediatras, São Paulo, v. 8, n. 2, p. 57-66, 2008.

BARDIN, L. Análise de conteúdo. Lisboa: Edições 70, 2011.

BIEDERMAN, J. Attention-deficit/ hyperactivity disorder: a selective overview. Biological Psychiatry, New York, v. 57. n. 11, p. 1215-1220, 2005.

BRASIL. Resolução 466 de dezembro de 2012. Estabelece diretrizes e normas de pesquisas envolvendo os seres humanos. Brasília: Conselho Nacional de Saúde, 2012.

BRZOZOWSKI, F. S.; CAPONI, S. Transtorno de déficit de atenção com hiperatividade: classificação e classificados. Physis: Revista de Saúde Coletiva, Rio de Janeiro, v. 19, n. 4, p. 1165-1187, 2009. 
CALIMAN, L. V. O. TDAH: entre as funções, disfunções e otimização da atenção. Psicologia em Estudo, Maringá, v. 13, n. 3, p. 559-566, 2008.

COSTA, G. A.; URZEDA, R. N.; SANTOS, F. R. M. et al. Programa de massagem terapêutica Shantala em crianças pré-escolares. Revista Movimenta, Goiás, v. 3, n. 2, 2010.

DESIDÉRIO, R. C. S.; MIYAZAKI, M. C. O. S. Transtorno de Déficit de Atenção/ Hiperatividade (TDAH): orientações para a família. Revista Semestral da Associação Brasileira de Psicologia Escolar e Educacional (ABRAPEE), São Paulo, v. 1, n. 1, p. 165-178, 2007.

FIGUEIRA, M. C.; SILVA, J. A. A importância de se identificar cedo se a criança é portadora de transtorno de déficit de atenção com hiperatividade TDAH. Caderno Multidisciplinar de Pós-Graduação da UCP, Pitanga, v. 1, n. 1, p. 65-78, 2010.

KUNRATH, L. H.; WAGNER, A. Reflexões acerca das estratégias educativas nas famílias com crianças com TDA/H. Cadernos de Educação-FaE/PPGE/UFPe. Pelotas, v. 32, p. 251- 265, 2009.

LARROCA, L. M.; DOMINGOS, N. M. TDAH - Investigação dos critérios para diagnóstico do subtipo predominantemente desatento. Revista Semestral da Associação Brasileira de Psicologia Escolar e Educacional, São Paulo, v. 16, n. 1, p. 113-123, 2012.

LOPES, C. Tuina: medicina manual Chinesa. São Paulo: Andreoli, 2010.

MERCATI, M. Tui Na: massagem para uma criança mais saudável e inteligente. São Paulo: Manole, 2000.

ORTEGA, F.; BARROS, D.; CALIMAN, L.; ITABORAHY, C.; JUNQUEIRA, L.; FERREIRA, C. P.A Ritalina no Brasil: produções, discursos e práticas. Interface, Botucatu, v. 14, n. 34, 2010.
PAIANO, M.; ANDRADE, B. B.; CAZZONI, E.; ARAÚJO, J. J.; WAIDMAN, M. A. P.; MARCON, S. S. Distúrbios de conduta em crianças do ensino fundamental e sua relação com a estrutura familiar. Revista Brasileira do Crescimento Desenvolvimento Humano, São Paulo, v. 17, n. 2, p. 111-121, 2007.

PHELAN, T. W. TDA/TDAH: Transtorno de déficit de atenção e hiperatividade. São Paulo: M Books do Brasil, 2005.

POLANCZYK, G. V.; CASENA, E. B.; MIGUEL, E. C.; REED, U. C. Transtorno de déficit de Atenção/hiperatividade: uma perspectiva científica. Clinics, São Paulo, v. 67, n. 10, p. 1125-1126, 2012.

REIS, G. V.; SANTANA, M. R. S. Transtorno de déficit de atenção e hiperatividade (Tdah): doença ou apenas rótulo? Anais do Sciencult, Paranaíba, v. 2, n. 1, p. 188-195, 2010.

ROHDE, L.A.;BARBOSA, G.; TRAMONTINA, S.; POLANCZYK, G. Transtorno de déficit de atenção/hiperatividade. Revista Brasileira Psiquiatria, São Paulo, v. 22, n. 2, p. 7-11, 2000.

ROSSI, E. Acunpunture and Tui Ná for hiperative children. Journal of Chinese Medicine, Garden City, n. 94, p. 09-17, 2010.

SAMPAIO, S. Transtorno de déficit de atenção/ hiperatividade: informações e orientações. 2004. Disponível em: <http://www. psicopedagogiabrasil.com.br/artigos_simaia_ tdah.htm>. Acesso em: 28 mar. 2013.

SCHILK, A. L. T. A educação além dos muros da escola. In: ENCONTRO NACIONAL SOBRE ATENDIMENTO HOSPITALAR: Reflexão do Evento Psicopedagógico Sedes Sapientia, 1., 2007, São Paulo. Anais... São Paulo: USP, 2007.

SENA, S. S.; SOUZA L. K. Percepção dos pais sobre amizade em crianças típicas e com TDAH. Psicologia Clínica, Rio de Janeiro, v. 25, n. 1, p. 53-72, 2013. 
SILVA, A. B. B. Mentes inquietas: entendendo melhor o mundo das pessoas distraídas, impulsivas e hiperativas. São Paulo: Gente, 2003.

SIRAICHI, J. T. G.; ARAUJO, J. P.; FERANDES, J. G. PINTO, R. R.; PIZZOLO A. R. D.; SANTOS, E. S. M.; OLIVEIRA A. R. G. MARTINELLI F. Percepção da massoterapeuta e da mãe sobre a intervenção da massagem tui na como terapia complementar na melhora da sintomatologia do transtorno de déficit de atenção com hiperatividade: um estudo de caso. Cadernos de Naturologia e Terapias Complementares, Palhoça, v. 2, n. 2, p. 83-91, 2013.

SINCLAIR, M. Massoterapia pediátrica. 2. ed. São Paulo: Manole, 2008.

TEIXEIRA, V. S. Compreendendo o TDAH: como lidar bem no lar e na escola. Disponível em: <http://www.abpp.com.br/artigos/33.htm>. Acesso em: 28 mar. 2013. 